\title{
A Posterior-Anterior Distinction between Scene Perception and Scene Construction in Human Medial Parietal Cortex
}

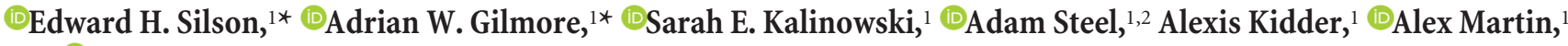 \\ and ${ }^{\odot}$ Chris I. Baker ${ }^{1}$ \\ ${ }^{1}$ Laboratory of Brain \& Cognition, National Institute of Mental Health, Bethesda, Maryland 20892-1366, and ${ }^{2}$ Wellcome Centre for Integrative \\ Neuroimaging, FMRIB, Nuffield Department of Clinical Neurosciences, University of Oxford, Oxford, OX3 9DU, United Kingdom
}

\begin{abstract}
Human retrosplenial complex (RSC), located in medial parietal cortex, has been implicated in numerous cognitive functions, including scene perception, spatial navigation, and autobiographical memory retrieval. Recently, a posterior-anterior distinction within RSC was proposed, such that posterior aspects process scene-related visual information (constituting a medial place area [MPA]), whereas anterior aspects process information that is vividly retrieved from memory, thereby supporting remembering and potentially navigation. Here, we tested this proposed distinction in a single group of participants (both male and female) using fMRI with both perceptual and mnemonic tasks. After completing a resting-state scan, participants performed a task that required constructing scenes from memory and completed a scene selectivity localizer task. We tested directly perceptual and mnemonic responses in MPA and an anterior, connectivity-defined region (CON), which showed strong functional connectivity with anterior parahippocampal place area. A double dissociation was observed, such that $\mathrm{CON}$ was more strongly activated during scene construction than was MPA, whereas MPA was more perceptually responsive than CON. Further, peak responses from the scene construction task were anterior to perceptual peaks in all but 1 participant and hemisphere. Finally, through analyses of the posterior-anterior response profiles, we identify the fundus of the parieto-occipital sulcus as a potential location for the crossover from perceptual to mnemonic representations and highlight a potential left-hemisphere advantage for mnemonic representations. Collectively, our results support a distinction between posterior and anterior aspects of the RSC, suggesting that more specific functional-anatomic terms should be used in its place in future work.
\end{abstract}

Key words: fMRI; memory; RSC; scene construction; scene perception

Significance Statement

The retrosplenial complex (RSC) has been implicated in vision, spatial cognition, and memory. We previously speculated on a potential posterior-anterior distinction within RSC for scene perception and memory-based scene construction/navigation. Here, we tested this distinction through a combination of resting-state, perceptual, and mnemonic task data. Consistent with our predictions, we demonstrate that perceptual responses peak consistently posterior of those elicited by memory-based scene construction within the broader RSC. Further, we highlight (1) the fundus of the parieto-occipital sulcus as a landmark for the transition between these representations, (2) the anterior bank of parieto-occipital sulcus as the point of maximal separation between these representations, and (3) identify a potential hemispheric asymmetry in mnemonic representations. These data support functional dissociations within RSC.

\section{Introduction}

Human medial parietal cortex is thought to play a direct role in multiple cognitive processes, including vision (Baldassano et al.,

\footnotetext{
Received May 14, 2018; revised Aug. 24, 2018; accepted 0ct. 15, 2018.

Author contributions: E.H.S., A.W.G., and C.I.B. wrote the first draft of the paper; E.H.S., A.W.G., S.E.K., A.M., and

C.I.B. designed research; E.H.S., A.W.G., S.E.K., and A.K. performed research; E.H.S., A.W.G., S.E.K., and A.S. analyzed data; E.H.S., A.W.G., S.E.K., A.S., A.K., A.M., and C.I.B. wrote the paper.

We thank members of the Laboratory of Brain and Cognition for helpful comments on earlier versions of the manuscript.

The authors declare no competing financial interests.

*E.H.S. and A.W.G. contributed equally to this work as co-first authors.
}

2013, 2016; Silson et al., 2016), memory (Buckner et al., 2008; Vilberg and Rugg, 2008; Ranganath and Ritchey, 2012; Gilmore et al., 2015), and spatial cognition (Marchette et al., 2014; Mitchell et al., 2018). Within medial parietal cortex, a region referred to as the "retrosplenial complex" (RSC) has received much attention and is implicated directly in scene perception (MacEvoy and Epstein, 2007) and tasks involving spatial memory (Epstein,

Correspondence should be addressed to Edward H. Silson at ed.silson@nih.gov.

https://doi.org/10.1523/JNEUROSCI.1219-18.2018

Copyright $\odot 2019$ the authors $\quad 0270-6474 / 19 / 390705-13 \$ 15.00 / 0$ 
2008; Marchette et al., 2015), navigation (Epstein and Higgins, 2007; Chrastil et al., 2017), topographical orientation (Kim et al., 2015), remembering past or imagining future events (Addis et al., 2007; Hassabis et al., 2007; Gilmore et al., 2016), the processing of spatial (and other) contextual associations (Bar and Aminoff, 2003), and the anchoring of internal spatial representations (Marchette et al., 2014), among others. The cortical expanse subsumed by the RSC label across these literatures is relatively large, spanning the parieto-occipital sulcus (POS) anteriorly to the splenium of the corpus callosum and dorsally to the precuneus and posterior cingulate cortex.

One could therefore summarize a consistent property of the RSC to involve the processing of scene-related information. This information can be derived from external sources, as with scene perception, or from internal sources, as when mnemonic information is required to construct a scene for the purposes of spatial navigation or reexperiencing a personal memory (Vann et al., 2009; Park et al., 2010; Mullally and Maguire, 2014; Robin, 2018). An important question therefore becomes the degree to which RSC may process scene-related information as a singular entity or the degree to which it may be comprised of distinct subregions that serve complementary roles.

The possibility of a heterogeneous organization within RSC arises from several lines of evidence. For example, several researchers (Nasr et al., 2011; Silson et al., 2016) have noted an apparent separation between the peak of perceptual scene selectivity in medial parietal cortex and the boundaries of RSC proper (i.e., Brodmann areas 29 and 30) (Morris et al., 2000). Additionally, studies using resting-state functional connectivity have suggested that anterior and posterior aspects of RSC (i.e., those primarily within the POS and those anterior to it) are correlated with distinct collections of brain regions (Baldassano et al., 2013, 2016; Silson et al., 2016). Based on the above observations, we proposed previously (Silson et al., 2016) a posterior-anterior distinction within RSC, such that posterior portions encode scenespecific visual information (within a "medial place area" [MPA]), whereas anterior portions may process information used to reconstruct scenes from memory.

In the current work, we sought to address directly the tension between a conceptual similarity across tasks associated with RSC and the possibility of functional distinctions within it. By conducting a single experiment within the same participants, we could also avoid anatomical ambiguities inherent in drawing conclusions across multiple datasets. Specifically, we tested for a posterior-anterior distinction between perceptually driven scene selectivity and memory-based scene construction within RSC using a combination of task-based and resting-state fMRI. Our research had three main goals. First, we wanted to replicate previous results (Silson et al., 2016) with respect to the anatomical location and functional characterization of MPA within the broader RSC. Second, we tested the hypothesis that a more anterior portion of RSC (termed "CON" for connectivity-defined ROI as a placeholder in Silson et al., 2016; a label we retain here) would activate during tasks that required constructing scenes from memory. In the current experiment, this was achieved by asking participants to both remember past and imagine future events, as both tasks have been associated with the construction of elaborate mental scenes (e.g., Hassabis et al., 2007). Third, to directly address the proposed posterior-anterior distinction, we tested for a double dissociation, whereby perceptual responses would result in more scene selectivity in MPA over CON, with memory-based scene reconstructions showing the opposite pattern. Our results confirm these predictions and identify sepa- rable regions within RSC for scene perception and scene construction, respectively. Importantly, these data suggest that the use of RSC as a label may be too imprecise, and that more specific functional-anatomic terms are preferable.

\section{Materials and Methods}

\section{Participants}

Twenty-two participants were recruited from the National Institutes of Health community and the Washington DC metro area. Of these, 1 participant was excluded due to excessive in-scanner motion, 1 was excluded due to a hardware malfunction midway through the protocol, and 1 was excluded for failing to reach performance criterion (see Postscan questionnaire). The remaining 19 participants ( 13 female) had a mean age of 23.5 years (range: $20-29$ years), were right-handed, neurologically healthy with normal or corrected-to-normal vision. Informed consent was obtained from all participants, and the experiment was approved by a National Institutes of Health Institutional Review Board (protocol 93-M-0170, clinical trials \#NCT00001360). All participants were monetarily compensated for their participation.

\section{Stimuli and tasks}

Resting-state scans. Resting-state data $(\sim 10 \mathrm{~min})$ were collected before the Memory Experiment. Subjects were instructed to fixate on a white cross presented at the center of the screen for the duration of the scan.

Memory experiment. Stimuli consisted of 144 short words and phrases that depicted common objects, locations, and activities (e.g., hiking, train ride), taken from a prior experiment (Gilmore et al., 2016). Stimuli ranged from 6 to 25 characters in length (mean length, 13.2 characters) and were balanced across participants such that they were equally likely to appear in each task condition. Stimuli (including intertrial fixation crosses) were presented in white 48-point Arial type against a dark gray background (Fig. 1A). Stimuli for this and the other in-scanner tasks were presented using PsychoPy software (Peirce, 2007) (RRID: SCR_006571) from a MacBook Pro laptop (Apple Systems).

The memory task used an adapted form of the Galton-Crovitz cuing paradigm (Crovitz and Schiffman, 1974). Across six runs, participants were cued on a trialwise basis to either recall specific events that had occurred in their past (the "Remember" condition) or envision specific events that might occur in their future (the "Future" condition). On each trial, either "Remember" or "Future" appeared on the screen and served to cue the participant to the required task. Below each temporal cue was an event probe, a short word or phrase meant to aid in the envisioning of a particular episode. Participants were instructed to think of a unique event in response to each probe that was specific in the time and place of its occurrence and to continue to reflect and elaborate upon the event until the end of each trial. Participants were given several practice trials before scanning, and all participants demonstrated an understanding of the task before data were collected. Trials lasted $10 \mathrm{~s}$, and a variable period of 2.5-7.5 s of fixation followed each trial to introduce temporal jitter and improve design efficiency (Miezin et al., 2000). For each condition, participants either remembered or imagined (as appropriate) 72 events, resulting in 144 total memory task trials.

Functional localizer experiment. Stimuli consisted of color images of scenes and faces and were used in prior laboratory studies (e.g., Silson et al., 2016). The images were sized at $5 \times 5^{\circ}$ of visual angle. The functional localizer task was completed across two scan runs following the Memory Experiment. In each run, participants fixated on a central cross while blocks of scenes and faces were presented in alternation (16 s and 20 images per block [ $300 \mathrm{~ms}$ per image, $500 \mathrm{~ms}$ blank]). Participants performed a one-back task during this time, responding via button-press whenever the same image (scene or face) appeared sequentially (Fig. 1B). On average, two repetitions occurred per block.

Postscan questionnaire. Upon exiting the scanner, participants completed two postscan questionnaires. One was the Vividness of Visual Imagery Questionnaire (VVIQ) (Marks, 1973). This questionnaire asks participants to mentally envision 16 items. Subjective ratings of the vividness of each mental image are made on a 5-point Likert-type scale $(1=$ no image at all; $5=$ as vivid as normal vision). Although the questionnaire asks for ratings with eyes open as well as eyes closed, we focused on 
A

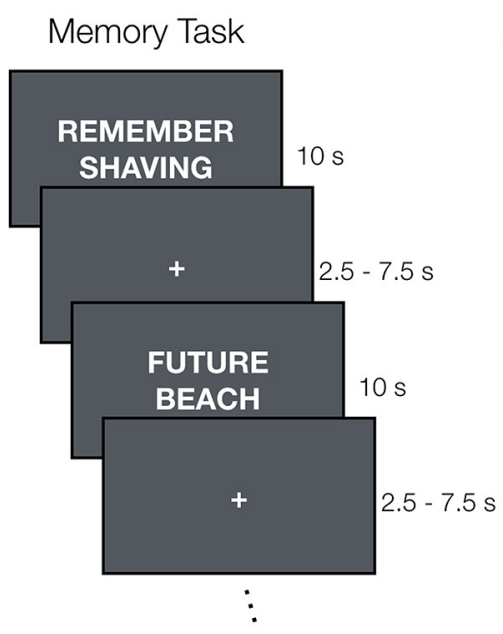

B

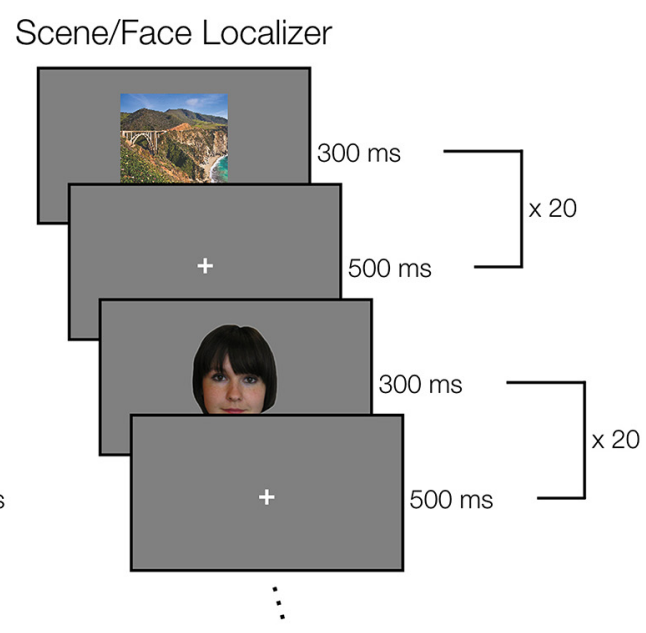

Figure 1. Mnemonic and functional localizer task schematics. $A$, During the mnemonic task, participants were given trial-wise instructions to either remember events from their past or imagine events that might occur in their future for the duration of a trial (10 s). Trials were separated by a variable ITI (2.5-7.5 s). Participants completed 6 runs of the mnemonic task. B, During functional localizer runs, participants viewed color images of scenes and faces $(5 \times 5 \mathrm{deg})$ presented in blocks (16 s) and performed a one-back task, indicating via button press when the same image (scene or face) appeared twice sequentially. Participants completed two runs of the localizer task.

the eyes-open rating as this matched the conditions during the memory task. In addition to the VVIQ, participants provided phenomenological ratings of vividness for each event they were asked to think about in the scanner. Judgments were made on a 4-point Likert-type scale $(1=$ not at all vivid; $4=$ extremely vivid). While providing these ratings, participants were also asked to identify any trials for which they were unable to bring a specific event to mind. Participants were excluded if they reported failures for $\geq 10 \%$ of the memory task trials. This resulted in the exclusion of a single participant who failed to think of a specific event for $24 \%$ of task trials. No other participants were excluded based on this criterion.

\section{fMRI data acquisition}

All images were acquired with a General Electric Discovery MR750 3.0T scanner, using a 32-channel head coil. Foam pillows helped stabilize head position for all participants, and foam earplugs attenuated scanner noise. A sensor was placed on each participant's left middle finger to record heart rate, and a respiration belt monitored participant's breathing. A high-resolution T1 structural image was obtained for each participant $\left(\mathrm{TE}=3.47 \mathrm{~ms}\right.$, repetition time $=2.53 \mathrm{~s}, \mathrm{TI}=900 \mathrm{~ms}$, flip angle $=7^{\circ}, 172$ slices with $1 \times 1 \times 1 \mathrm{~mm}$ voxels). All functional images were acquired using a BOLD-contrast sensitive three-echo echo-planar sequence (ASSET acceleration factor $=2, \mathrm{TE}=12.5,27.7$, and $42.9 \mathrm{~ms}$, flip angle $=75^{\circ}, 64 \times 64$ matrix, in-plane resolution $=3.2 \times 3.2 \mathrm{~mm}$, slice thickness $=3.5 \mathrm{~mm}$ ). Repetition times and acquired slices varied across different task conditions to be consistent with relevant prior work for each task. The memory task used a $2500 \mathrm{~ms}$ repetition time, with 35 slices collected. The Scene Localizer task required a $2000 \mathrm{~ms}$ repetition time, with 30 slices collected (retaining ventral surface coverage but losing some of the motor strip). Finally, resting-state scans used a $2200 \mathrm{~ms}$ repetition time, with 33 slices. All slices were collected obliquely and were manually aligned to the anterior commissure-posterior commissure axis.

\section{fMRI data preprocessing}

Data were preprocessed using AFNI (Cox, 1996) (RRID:SCR_005927). Initial steps for each time series included frame-by-frame rigid-box realignment to the first volume of each run, slice-timing correction, and despiking. The first 4 frames of each run were discarded to allow for T1 equilibration effects. Data from all three acquired echoes were then registered to each subject's T1 image and combined to remove additional thermal and physiological noise using multiecho independent components analysis (Kundu et al., 2012, 2013, 2017; Power et al., 2018). This procedure initially uses a weighted average of the three echo times for each scan run to reduce thermal noise within each voxel. It subsequently performs a spatial independent components analysis to separate time series components and uses the known properties of $\mathrm{T}_{2}{ }^{*}$ signal decay to separate putatively neuronal BOLD components from putative noise components. This is accomplished by comparing each component with a model that assumes a temporal dependence in signal decay (i.e., "BOLD-like") and with a different model that assumes temporal independence (i.e., "non-BOLD-like"). Components with a strong fit to the former and a poor fit to the latter model are retained for subsequent analysis (for further details, see Kundu et al., 2012). This procedure was conducted using default options in AFNI's tedana.py function. Multiecho independent components analysis processed data from each scan were then aligned across runs for each participant.

\section{fMRI data analysis}

Memory analysis. Analyses were conducted using a GLM and the AFNI programs 3dDeconvolve and 3dREMLfit. The data at each time point were treated as the sum of all effects thought to be present at that time point and the time series was compared against a Generalized Least Square (GLSQ) model fit with REML estimation of the temporal auto-correlation structure. Responses were modeled by convolving a standard gamma function with a $10 \mathrm{~s}$ square wave for each of the two conditions of interest (Remember, Future). Estimated motion parameters were included as additional regressors of noninterest, and fourth-order polynomials were included to account for slow drifts in the MR signal over time. Significance was determined by comparing the $\beta$ estimates for each condition (normalized by the grand mean of each voxel for each run) against baseline. Each memory run lasted $382.5 \mathrm{~s}$.

Scene selectivity analysis. A GLM approach was also used to analyze the functional localizer data. Specifically, a response model was built by convolving a standard gamma function with a $16 \mathrm{~s}$ square wave for each condition (scene, face) and compared against the activation time courses using Generalized Least Square regression. Motion parameters and four polynomials accounting for slow drifts were included as regressors of no interest. To derive the response magnitude per condition, $t$ tests were performed between the condition-specific $\beta$ estimates (normalized by the grand mean of each voxel for each run) and baseline. For each participant, we analyzed the two localizer runs separately. A contrast of the response magnitudes provided our index of "scene selectivity" (i.e., of the degree to which responses evoked by presentations of scenes were greater than those evoked by faces). Localizer runs lasted $304 \mathrm{~s}$.

Sampling of data to the cortical surface. In each participant, the analyzed functional localizer and memory task data were projected onto surface reconstructions of each individual participant's hemispheres using the Surface Mapping with AFNI (SUMA) software. First, data were aligned to high-resolution anatomical scans (align_epi_anat.py). Once aligned, these data were projected onto the cortical surface (3dVol2Surf) and smoothed by a $5 \mathrm{~mm}$ FWHM Gaussian kernel. All subsequent analyses were conducted in surface space. Where appropriate, both sides of the statistical contrasts are plotted across the cortical surfaces.

ROIs. Initially, we defined MPA in each participant and hemisphere for each localizer runs separately. The MPA was consistently located within the ventral and posterior portion of the POS. To ensure independence when calculating the magnitude of scene selectivity, which we define as the extent to which the response to Scenes is greater than the response to Faces ( $t$ value, Scenes $>$ Faces), we first defined MPA using the data from the first run and extracted the scene-selective indices from the second run. The process was then reversed and repeated (with the second run defining MPA, and then extracting the scene-selective indices 
from the first run) and the average of the two orders was computed. To define the connectivity-based ROI, we first divided parahippocampal place area (PPA) approximately evenly along the posterior-anterior axis, creating two ROIs (posterior PPA [pPPA], anterior PPA [aPPA]). Next, we calculated the mean resting-state time-series across all cortical nodes in each ROI. For every cortical node on the surface, we then calculated the difference in the connectivity with each ROI separately. That is, we computed the differential connectivity with PPPA and aPPA, lorespectively. Consistent with our previous report (Silson et al., 2016), this analysis revealed a region largely anterior to MPA that exhibited significantly stronger connectivity with aPPA over pPPA. We adopt the nomenclature from our previous report and refer to this connectivity-defined region as "CON." The group average contrast of pPPA-aPPA (thresholded at $p<$ $1.4^{-4}$ ) was used to define CON, which was then applied to each individual participant.

Calculating perceptual versus mnemonic response profiles within RSC. To estimate an approximate crossover point between predominantly perceptual and predominantly mnemonic processing in RSC, we transformed the group-based MPA and CON peaks back into native space for each participant. A line was then drawn between these two peaks, and all vertices crossed by this line were included as a "line ROI." To account for differences in the overall response strengths of the perceptual (scenes $>$ faces $t$ value) and mnemonic (remember $>$ baseline, future $>$ baseline $t$ value) tasks, the responses from all vertices and all tasks were extracted and normalized within each participant, resulting in values between 0 and 1.

\section{Results}

The overarching goal of the current study was to assess the posterior-anterior relationship within RSC between responses elicited by perceiving scene images and those elicited through internal construction of scenes from memory. Before describing these results, however, we describe briefly the results of our behavioral assessments.

\section{Remembered events more vivid than imagined future events}

First, we compared the individual participant vividness ratings for both mnemonic conditions (Remember, Future) using paired $t$ tests (two-tailed). Consistent with previous work (D'Argembeau and Van der Linden, 2004; Arnold et al., 2011; Gilmore et al., 2016, 2018), vividness ratings were on average significantly higher for Remember over Future trials $\left(t_{(17)}=4.43\right.$, $p=0.003)$. Second, we calculated the proportion of missed trials (i.e., those for which a participant was unable to bring a specific scenario to mind). On average, participants missed very few trials $(\sim 4 \%$ in both tasks), and these proportions were not significantly different between mnemonic conditions $\left(t_{(17)}=\right.$ $1.50, p=0.15)$.

\section{Vividness ratings correlate with VVIQ scores}

Next, we computed the correlation (Pearson's) between each participant's vividness ratings for both mnemonic conditions and their eyes-open VVIQ ratings. Significant positive correlations were observed between VVIQ ratings and both the mean Remember $\left(r_{(16)}=0.56, r^{2}=0.31, p=0.02\right)$ and mean Future $\left(r_{(16)}=0.50, r^{2}=0.25, p=0.04\right)$ subjective vividness ratings.

\section{ROIs: medial place area and connectivity-defined CON}

To test the posterior-anterior relationship between visual scene perception and scene construction from memory, we defined two ROIs within the broader RSC that were independent of our memory task. First, in each participant and hemisphere, we defined the MPA using the contrast of Scenes $>$ Faces. MPA was located consistently within the ventral and posterior bank of the POS and did not appear to extend into RSC proper (i.e., BA 29/30)
(Fig. 2A). We previously identified a retinotopically sensitive region of medial parietal cortex that overlapped with MPA (Silson et al., 2016), and the location of MPA in the current data is consistent with this previous characterization. Second, consistent with our own (Silson et al., 2016) and other (Baldassano et al., 2013) previous work, we also identified a functional-connectivity region (referred to as $\mathrm{CON}$ ), by calculating the differential resting-state connectivity between pPPA and aPPA (see Materials and Methods; Fig. $2 B$ ). This analysis revealed an anterior region of RSC, which exhibited significantly stronger connectivity with aPPA than pPPA. In general, this region was located largely anterior of MPA, extending anteriorly from the fundus of the POS, onto the anterior gyrus and toward the posterior cingulate and precuneus (Fig. 2C). We assessed the spatial overlap between MPA and CON in each individual participant, by calculating the percentage of cortical nodes/vertices in MPA shared by $\mathrm{CON}$ and vice versa and then computed the average. At the selected statistical thresholds, this analysis revealed on average a shared region of $\sim 39 \%$ and $\sim 43 \%$ for the left and right hemispheres, respectively, which did not differ significantly between hemispheres $\left(t_{(18)}=1.02, p=0.32\right)$. To account for this spatial overlap, only cortical nodes/vertices unique to each ROI were included in subsequent analyses (Average number of included nodes/vertices: Left MPA [371], Right MPA [612], Left CON [1079], Right CON [1070], Left overlap [337], Right overlap [497]).

\section{Remember and future mnemonic responses}

Separate analyses were performed contrasting each event construction condition (Remember, Future) to baseline. The group average contrast of Remember $>$ baseline (thresholded at $p=$ $2.0^{-5}$ ) is shown on partially inflated medial surfaces of both hemispheres of a representative participant in Figure $3 A$. In the left hemisphere, significantly greater responses during remember trials were present within RSC, overlapping largely with, but also extending beyond, the CON ROI (Fig. $3 A$ ). In the right hemisphere, we also observed clusters that overlapped largely with the CON ROI. On the lateral surface, significant responses to remember trials were also observed anterior of OPA, in the approximate location of the angular gyrus/caudal inferior parietal lobule, but these lateral effects were only present in the left hemisphere. Ventrally, significant responses to remember trials overlapped with aPPA and were also evident in the superior frontal gyrus, again with a more pronounced effect in the left hemisphere (Fig. 3A). At the whole-brain level, Future trials exhibited a qualitatively similar pattern to what was observed for Remember trials, albeit it with reduced areal extent in the left hemisphere and without a significant aPPA cluster on the right (Fig. 3B). Unthresholded maps appeared similar in both hemispheres and both tasks.

To explore further these effects, we calculated in each participant the median $t$ value for (1) Remember $>$ baseline and (2) Future > baseline, in each ROI (MPA, CON) and hemisphere, respectively (Fig. 3C,D). These values were submitted to a three-way repeated-measures ANOVA with within-subject factors of ROI (MPA, CON), Condition (Remember, Future), and Hemisphere (Left, Right). The main effect of ROI $\left(F_{(1,18)}=12.93\right.$, $p=0.002$, partial $\left.\eta^{2}=0.42\right)$ was significant, reflecting on average larger values in CON over MPA across both conditions. The main effect of Condition $\left(F_{(1,18)}=9.23, p=0.007\right.$, partial $\eta^{2}=$ 0.34 ) was significant, reflecting on average larger values for Remember over Future trials across both ROIs. The main effect of Hemisphere $\left(F_{(1,18)}=47.09, p=0.00002\right.$, partial $\left.\eta^{2}=0.72\right)$ was 


\section{A}

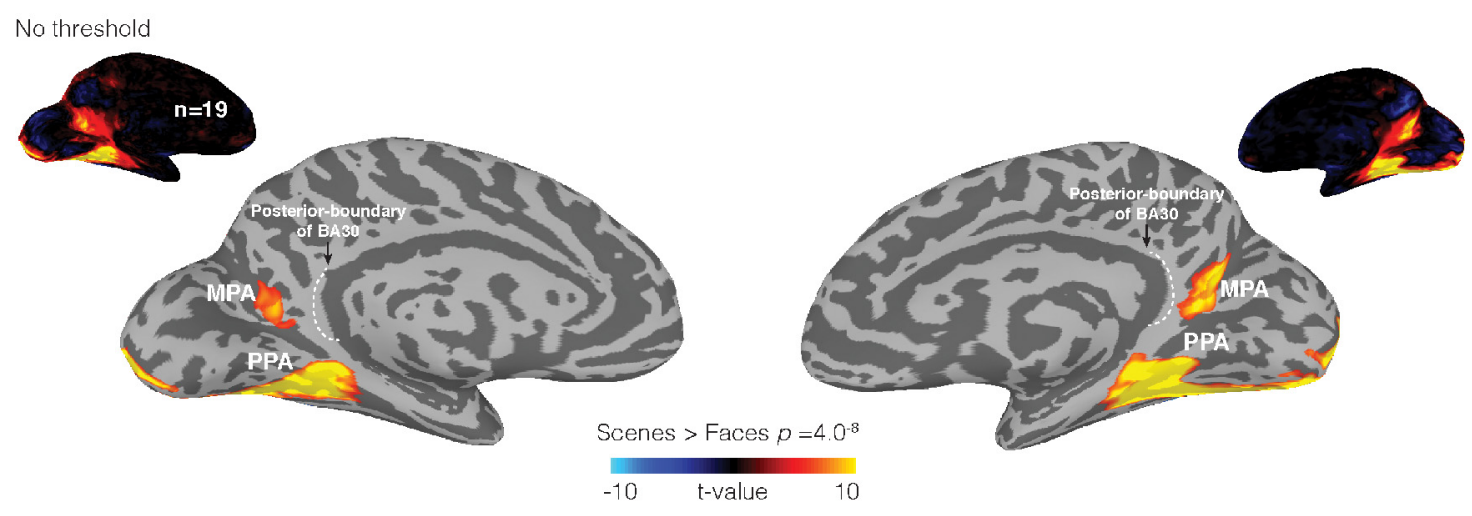

B
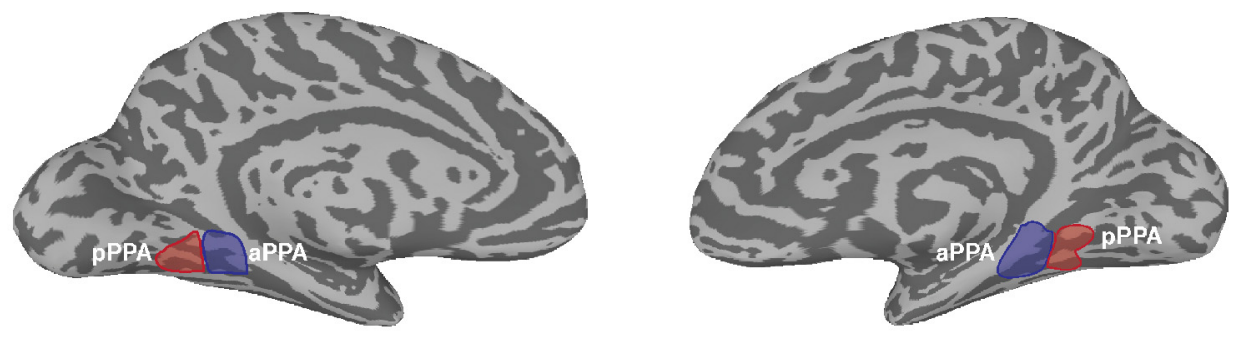

\section{C}

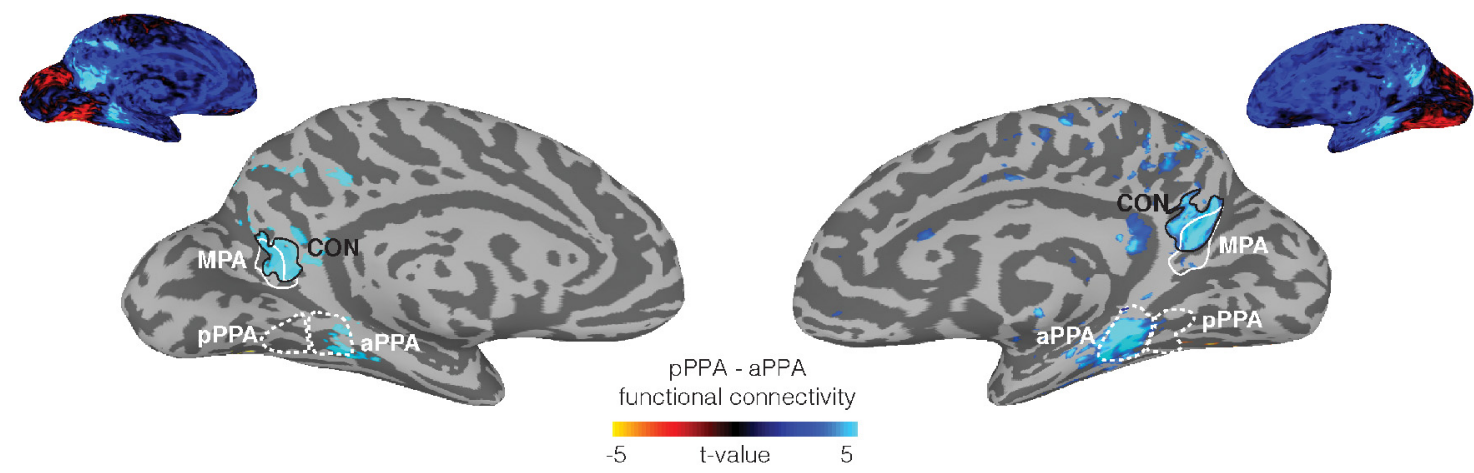

Figure 2. Functional localization and spatial overlap of scene-selective and connectivity-derived ROls. $A$, Group average $(n=19)$ scene-selective regions are shown on medial views of both the left and right hemispheres, respectively (Scenes $>$ Faces, $p=4.0^{-8}$ ). Inset, Unthresholded versions. In both hemispheres, the MPA is located largely within the ventral and posterior bank of the POS. The posterior boundary of BA30, redrawn from Brodmann (1909) and Vann et al. (2009), is overlaid (white dashed line). $\boldsymbol{B}$, The pPPA (red area) and aPPA (blue area) ROls are shown on medial surfaces of both hemispheres. C, Group average differential connectivity maps between pPPA and aPPA are shown on medial views of the left and right hemispheres, respectively $\left(p=4.1^{-4}\right)$. Dashed white lines indicate the PPPA and aPPA ROIs, with unthresholded version inset above. A region showing significant differential connectivity with aPPA (referred to as CON) was found in medial parietal cortex largely anterior to MPA in both hemispheres (white line indicates MPA; black line indicates CON).

also significant, reflecting on average larger values in the left over right hemisphere across both ROIs and conditions. Both the ROI $\times$ Hemisphere $\left(F_{(1,18)}=5.85, p=0.026\right.$, partial $\left.\eta^{2}=0.24\right)$ and Condition $\times$ Hemisphere $\left(F_{(1,18)}=4.56, p=0.04\right.$, partial $\eta^{2}=0.21$ ), interactions were significant, reflecting on average a larger difference between ROIs and a larger difference between conditions in the left than right hemispheres, respectively. All other interactions were not significant ( $p>0.05$, in all cases).

\section{Scene perception versus scene construction from memory in RSC}

We anticipated a posterior-anterior division between perceptual responses (i.e., scene-selective) more posteriorly and mnemonic responses more anteriorly within the broader RSC. Specifically, we predicted greater perceptual responses for MPA over CON and greater mnemonic responses for CON over MPA, a double dissociation between ROI and Task.

Accordingly, we calculated the median perceptual response (given by the $t$ value of Scenes $>$ Faces) and the median mnemonic response (given by the $t$ value of Remember $>$ baseline) in each ROI and hemisphere, respectively (Fig. 4A,B). These data were subjected to a three-way repeated-measures ANOVA with within-subject factors of ROI (MPA, CON), Task (Perceptual, Mnemonic), and Hemisphere (Left, Right). The main effect of $\operatorname{ROI}\left(F_{(1,18)}=21.01, p=0.0002\right.$, partial $\left.\eta^{2}=0.54\right)$ was significant, reflecting on average larger values in MPA over CON across analyses. The main effect of Task was significant $\left(F_{(1,18)}=20.62\right.$, $p=0.0002$, partial $\eta^{2}=0.53$ ), which reflects on average the larger $t$ values in the perceptual over mnemonic task. The main effect of Hemisphere was also significant $\left(F_{(1,18)}=7.26, p=0.01\right.$, 
A
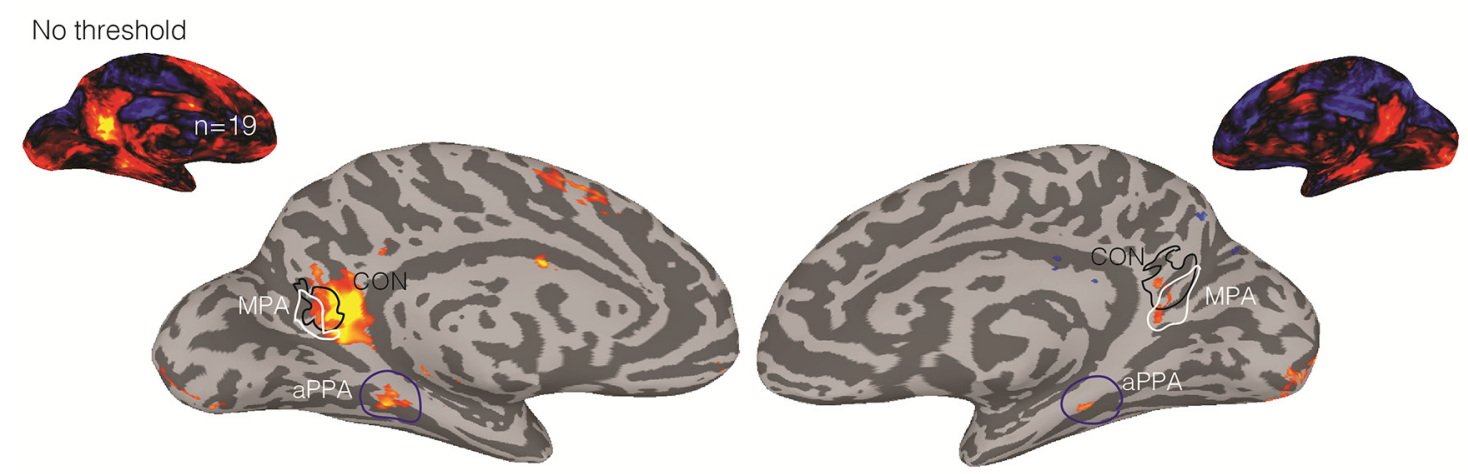

Remember $>$ Baseline $p=2 \cdot 0^{-5}$

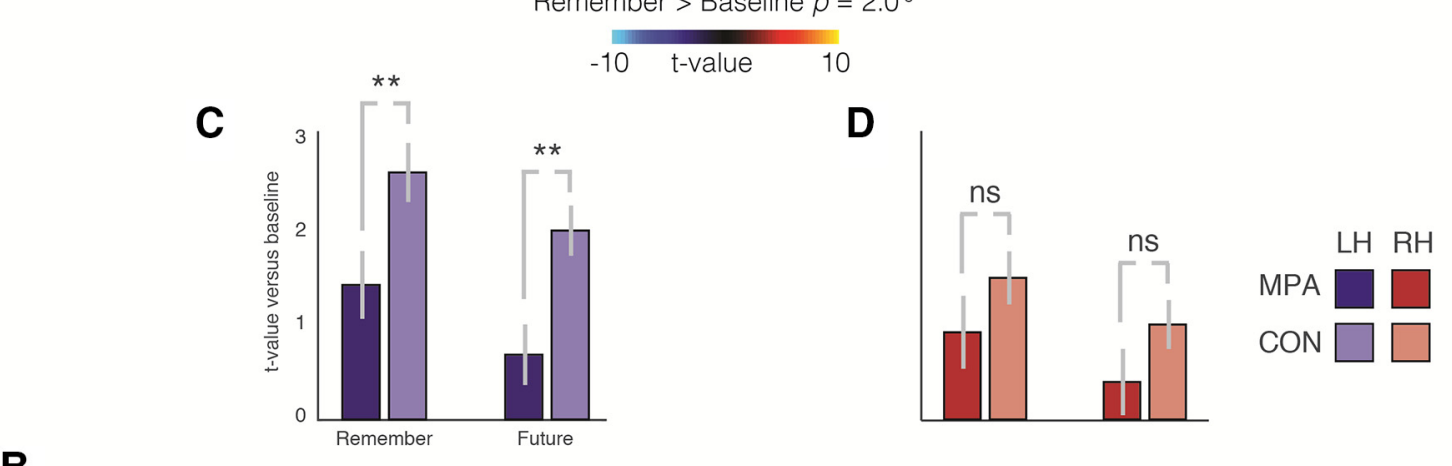

B
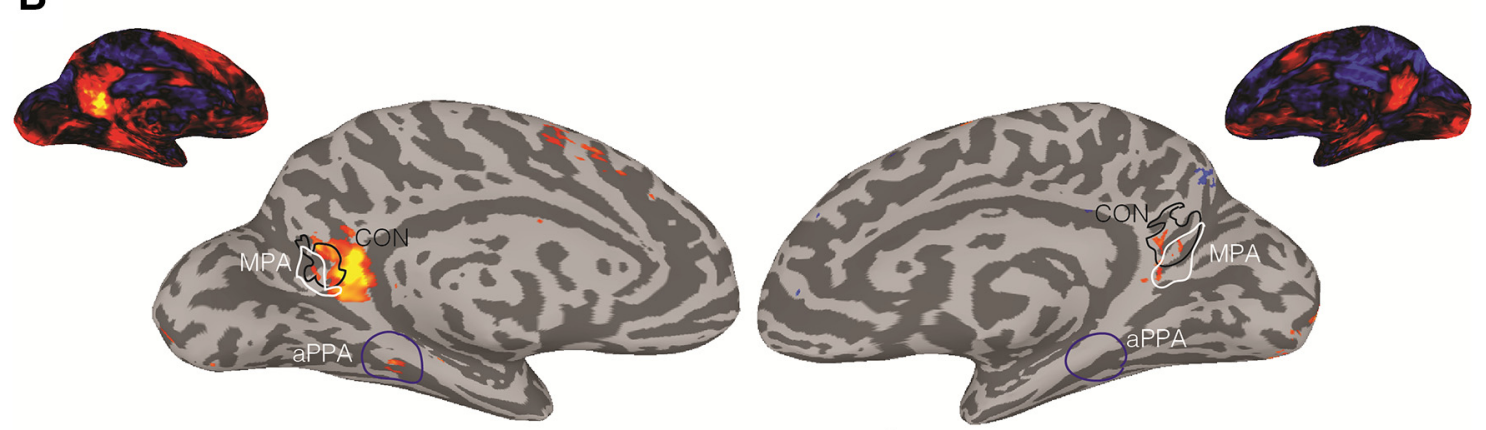

Future $>$ Baseline $p=2.0^{-5}$

-10 t-value 10

Figure 3. Mnemonic responses in medial parietal cortex. A, Group average results for Remember $>$ Baseline $\left(p=2.0^{-5}\right)$ are shown on medial views of the left and right hemispheres, respectively. Inset, Unthresholded versions. In the left hemisphere (left), we observe a medial parietal memory region that overlaps and extends beyond CON (black line), but importantly falls largely anterior of MPA (white line). An additional small region in aPPA (blue circle) is also present. A similar, albeit reduced, pattern of responses is observed in the right hemisphere, including a small region in aPPA. $\boldsymbol{B}$, Group average results for Future $>$ Baseline are shown and highlight a very similar pattern of results to those in $\boldsymbol{A}$, although reduced in magnitude. $\boldsymbol{C}$, Error bars indicate the mean of the median $t$ values for each condition (Remember, Future) versus baseline in MPA and CON in the left hemisphere. $\boldsymbol{D}$, Same as in $\boldsymbol{C}$, but for the right hemisphere. In both hemispheres, mnemonic responses are larger in CON than MPA and are larger for remembered over imagined future events. In this and all subsequent bar plots, error bars indicate the SEM across participants. ${ }^{* *} p<0.01$.

partial $\left.\eta^{2}=0.28\right)$, reflecting on average larger values in the left than right hemisphere across ROIs and tasks. The Hemisphere $X$ ROI interaction $\left(F_{(1,18)}=14.89, p=0.001\right.$, partial $\left.\eta^{2}=0.45\right)$ was significant, reflecting on average larger perceptual values in the right hemisphere for MPA and larger mnemonic values in CON for the left hemisphere. The Hemisphere $\times$ Task interaction $\left(F_{(1,18)}=14.21, p=0.001\right.$, partial $\left.\eta^{2}=0.44\right)$ was also significant, reflecting on average larger perceptual values in the right hemisphere but larger mnemonic values in the left hemisphere across ROIs. The Hemisphere $\times$ ROI by Task interaction $\left(F_{(1,18)}=1.97\right.$, $p=0.17$, partial $\eta^{2}=0.10$ ) was not significant, but importantly the ROI $\times$ Task interaction was significant $\left(F_{(1,18)}=80.35, p=\right.$ $4.67^{-8}$, partial $\eta^{2}=0.82$ ).

Given the significant ROI $\times$ Task interaction, we tested the ROI differences directly in each hemisphere using paired $t$ tests (two-tailed) (Fig. 4A,B). In both hemispheres, perceptual responses were significantly greater in MPA than CON, whereas mnemonic responses were significantly greater in CON over MPA in the left hemisphere, but not the right, although the data trended in the prediction direction (Left Hemisphere, MPA vs CON perceptual: $t_{(18)}=5.77, p=0.00002$; MPA vs CON remember: $t_{(18)}=4.17, p=0.002$; Right Hemisphere, MPA vs CON perceptual: $t_{(18)}=8.26, p=1.53^{-7}$; MPA vs CON remember: $\left.t_{(18)}=1.95, p=0.06\right)$.

For completeness, we also compared perceptual responses against the responses derived from the Future $>$ baseline contrast using the same three-way repeated-measures ANOVA as above. As depicted in Figure $4 C, D$, these results largely replicated those observed in the Remember $>$ baseline contrast: there were significant main effects of ROI $\left(F_{(1,18)}=24.86, p=0.0009\right.$, partial 
A

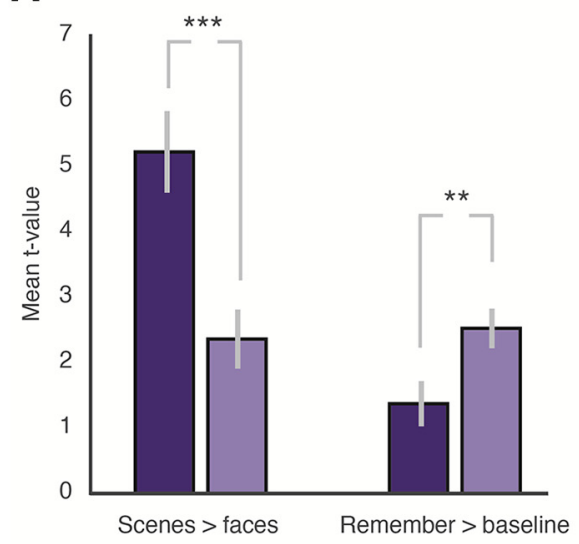

C

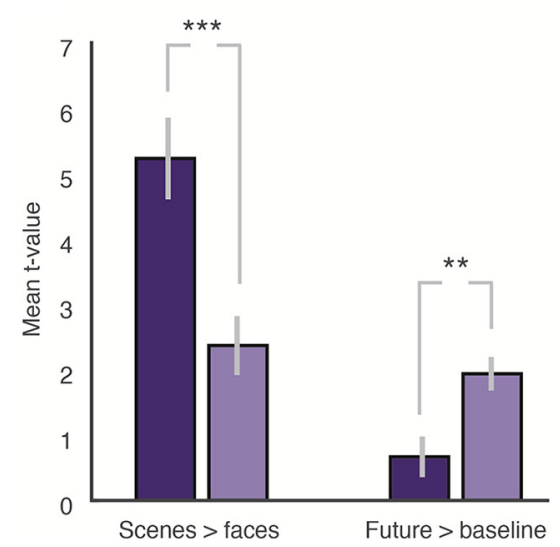

B

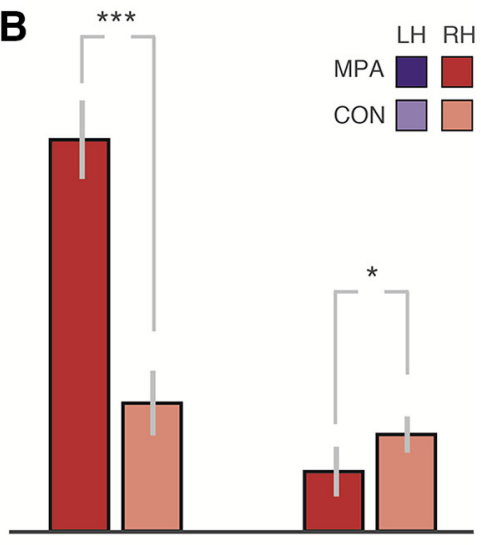

D

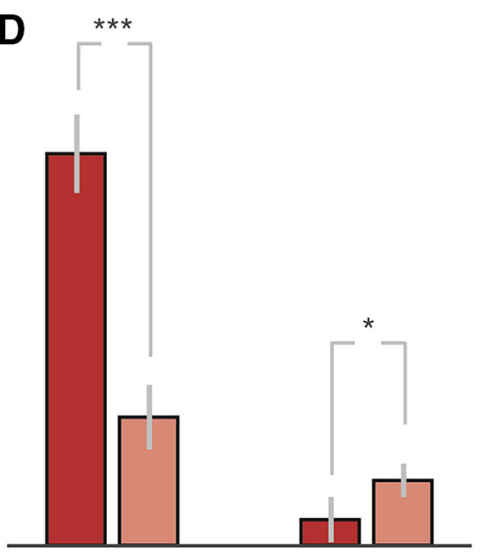

Figure 4. Perceptual (scene-selective) versus mnemonic (Remember, Future) responses in medial parietal cortex. $\boldsymbol{A}$, Error bars indicate the mean of the median $t$ values for both tasks (Scenes $>$ Faces, Remember $>$ Baseline) in each ROI (MPA, CON) in the left hemisphere. Perceptual responses are significantly greater in MPA, but remembered events are significantly greater in CON. $\boldsymbol{B}$, Same as in $\boldsymbol{A}$, but for the right hemisphere. $\boldsymbol{C}, \boldsymbol{D}$, Same as in $\boldsymbol{A}$ and $\boldsymbol{B}$, but for Future $>$ Baseline. ${ }^{* * *} p<0.001$. ${ }^{* *} p<0.01$. ${ }^{*} p<0.05$.

$\left.\eta^{2}=0.58\right)$ and Task $\left(F_{(1,18)}=29.59, p=0.0003\right.$, partial $\eta^{2}=$ $0.62)$, but the main effect of Hemisphere was not significant $\left(F_{(1,18)}=4.03, p=0.06\right.$, partial $\left.\eta^{2}=0.18\right)$. Significant interactions included Hemisphere $\times$ ROI $\left(F_{(1,18)}=18.86, p=\right.$ 0.0003 , partial $\left.\eta^{2}=0.51\right)$, Hemisphere $\times$ Task $\left(F_{(1,18)}=5.84\right.$, $p=0.005$, partial $\left.\eta^{2}=0.37\right)$, and ROI $\times \operatorname{Task}\left(F_{(1,18)}=58.92\right.$, $p=4.39^{-7}$, partial $\left.\eta^{2}=0.76\right)$. The Hemisphere $\times$ ROI $\times$ Task interaction $\left(F_{(1,18)}=1.73, p=0.20\right.$, partial $\left.\eta^{2}=0.08\right)$ was not significant. Following the significant ROI $\times$ Task interaction, we tested the differences directly in each hemisphere separately using paired $t$ tests (two-tailed) (Fig. 4C,D). In both hemispheres, perceptual responses were significantly greater in CON over MPA in the left hemisphere, but not the right, although the data trended in the prediction direction (Left Hemisphere, MPA vs CON perceptual: $t_{(18)}=5.77, p=$ 0.00002; MPA vs CON remember: $t_{(18)}=4.17, p=0.002$; Right Hemisphere, MPA vs CON perceptual: $t_{(18)}=8.26, p=$ $1.53^{-7}$; MPA vs CON remember: $\left.t_{(18)}=1.95, p=0.06\right)$.

\section{Potential hemispheric differences in scene construction from memory}

A consistent feature of our data is the apparently stronger responses during scene construction in the left over right hemisphere, for both mnemonic conditions. We investigated this

potential hemispheric difference in a number of ways. First, we defined a medial parietal ROI anatomically in each participant and hemisphere that spanned the entire POS from the posterior to anterior banks and extended ventrally from the dorsal most tip of POS to the calcarine sulcus (see, e.g., Fig. 5A, inset). This anatomical ROI allowed us to calculate the distribution of mnemonic responses across the broader RSC independently of the statistical thresholding of our main ROIs (MPA, CON). To take into account differences in the absolute number of included cortical nodes across participants, we divided each distribution by the total number of included nodes for that participant, thus representing distributions proportionally. Figure $5 A, B$ depicts the average distribution of mnemonic responses in the anatomical ROI for both hemispheres and mnemonic conditions, respectively. In both conditions, the distribution of mnemonic responses for the left hemisphere is shifted rightwards (reflecting larger response magnitudes compared with baseline) relative to the distribution of mnemonic responses for the right hemisphere.

Second, to quantify these apparent shifts, we calculated the median $t$ value for both conditions in each hemisphere and participant. For both conditions, there was a significant difference in the median $t$ values between hemispheres (Left hemisphere vs Right hemisphere, Remember $>$ baseline: $t_{(18)}=4.37, p=0.0002$; Future $>$ baseline: $t_{(18)}=5.07, p=0.00002$; Fig. 5C,D).

Third, we calculated the proportion of nodes in each hemisphere with a $t$ value $>3.83$ (corresponding to a $p$ value of 0.0001 ) in both conditions. Consistent with the previous analyses, there were on average significantly more suprathreshold nodes in the left than right hemispheres for both mnemonic conditions (Left hemisphere vs Right hemisphere, Remember > baseline: $t_{(18)}=3.94, p=0.001$; Future $>$ baseline: $t_{(18)}=2.97$, $p=0.008$; Figure $5 E, F)$.

\section{Scene construction peaks anterior of scene perception within RSC}

The current data suggest that perceptual representations of scenes are located largely in the posterior and ventral bank of POS, whereas mnemonic representations, elicited by constructing scenes either from remembered events or imagined future events, extend anteriorly into regions of RSC, including the posterior cingulate and precuneus. To investigate this in more detail, we determined the peak responses in both hemispheres for both scene perception and scene construction in each participant (Fig. $6 A, B)$. Across participants, the peak of perceptual responses (peak of scene selectivity) in RSC was never anterior of the peak for remembered events (Fig. 6A) and was only anterior of the 
A
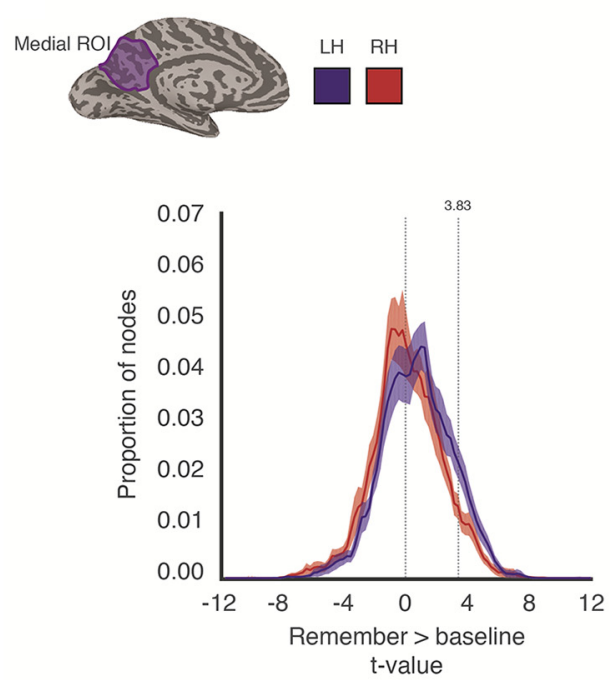

B

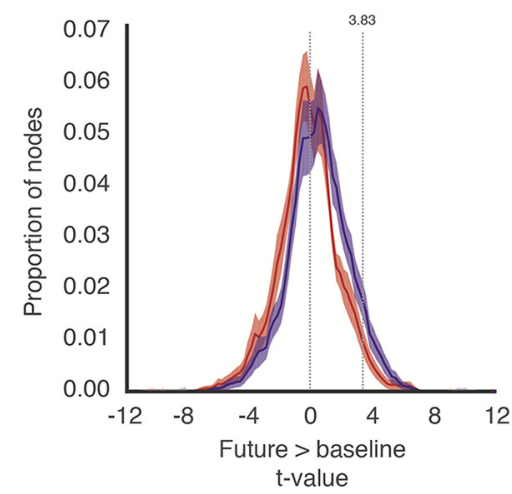

C
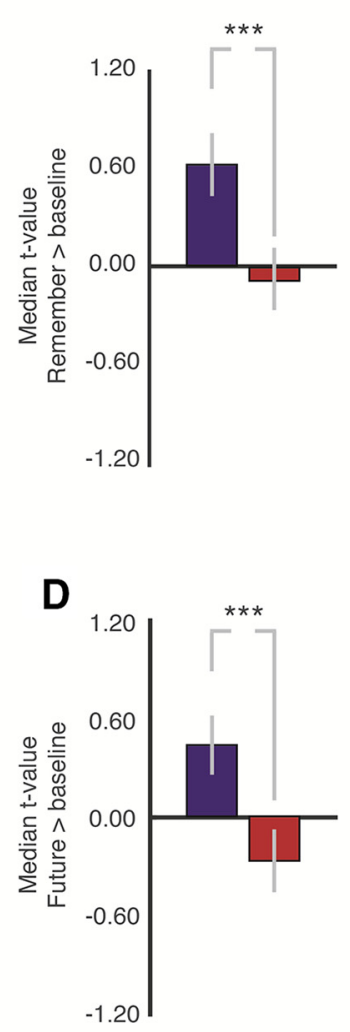

E

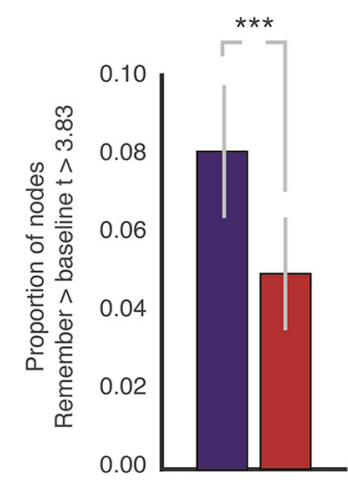

$\mathbf{F}$

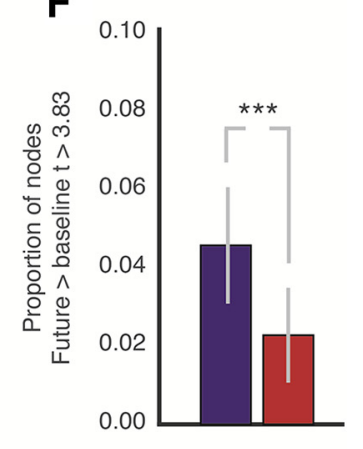

Figure 5. Hemispheric asymmetries in mnemonic representations. $A$, In each participant and hemisphere, an anatomical ROl for medial parietal cortex was defined. The posterior boundary of this ROl tracked the posterior bank of the POS to the dorsal bank of the calcarine sulcus and extended anteriorly to the splenium of the corpus callosum, including the precuneus. An example is shown for the left hemisphere of a single participant (purple ROI). From this ROI, we calculated the distribution of t values for the contrast of Remember $>$ Baseline in both the left (blue line) and right (red line) hemispheres. Vertical dashed line at $t=0$ indicates the boundary between baseline (negative values) and Remember responses (positive values). Dashed line at $t=3.83$ indicates the threshold applied to these data for establishing significant responses. There is a clear rightward shift in the distribution for the left hemisphere, relative to the right. $\boldsymbol{B}$, Same as in $\boldsymbol{A}$, but for Future $>$ Baseline. Solid line indicates the mean. Shaded area represents the SEM across participants. $C$, Error bars indicate the mean of the median $t$ value from the anatomical ROI in both hemispheres. The left hemisphere contained on average significantly higher positive $t$ values. $\boldsymbol{D}$, Same as in $\boldsymbol{C}$, but for Future $>$ Baseline. $\boldsymbol{E}$, Bars represent the proportion of suprathreshold nodes from the anatomical ROI. The left hemisphere contained a significantly higher proportion of suprathreshold nodes. $\boldsymbol{F}$, Same as in $\boldsymbol{E}$, but for Future $>$ Baseline. ${ }^{* * *} p<.001$.

peak for imagined future events in the right hemisphere of a single participant (Fig. 6B).

\section{Posterior-anterior perceptual versus mnemonic response profiles within RSC}

Although the previous analysis demonstrated that peak perceptual responses were consistently posterior of peak mnemonic responses in both hemispheres, it did not speak to where the transition between perceptual and mnemonic responses might occur within the broader RSC. To explore this further, we defined in each participant a line ROI that spanned POS from the posterior to anterior banks, running through the peaks within the group-based MPA and CON, respectively (see, e.g., Fig. 7A). To compare the two analyses directly, we first extracted perceptual (scenes $>$ faces $t$ value) and mnemonic (remember $>$ baseline, future $>$ baseline $t$ value) responses from the ROI and subsequently normalized them (between 0 and 1 ) within each participant, before averaging across participants. The group averaged posterior-anterior response profiles are shown in Figure $7 B-E$ for both hemispheres. These profiles reveal a striking difference between the relative strength of perceptual and mnemonic responses as a function of posterior-anterior location within RSC. At the posterior bank of POS, the relative magnitudes of perceptual and mnemonic responses are largely comparable, but unlike perceptual responses, which exhibit a sharp rise peaking posterior of the fundus of the POS and then a gradual decrease anteriorly, mnemonic responses show a more gradual rise, peaking anterior of the fundus of the POS in both hemispheres and for both mnemonic conditions (Fig. $7 B-E$ ). Indeed, the largest gap between perceptual and mnemonic profiles occurs at the anterior bank of POS, extending anteriorly and dorsally toward the posterior cingulate and precuneus. These data, although purely qualitative, suggest the fundus of the POS as a potential transition point between perceptual and mnemonic responses within RSC, but also highlight the anterior bank as the region where perceptual and mnemonic responses become maximally separable.

\section{Discussion}

Here, we systematically compared the posterior-anterior relationship between perceptual representations of scenes and 
A

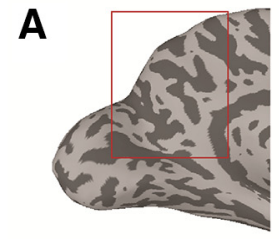

Scene-selective

Remember > baseline
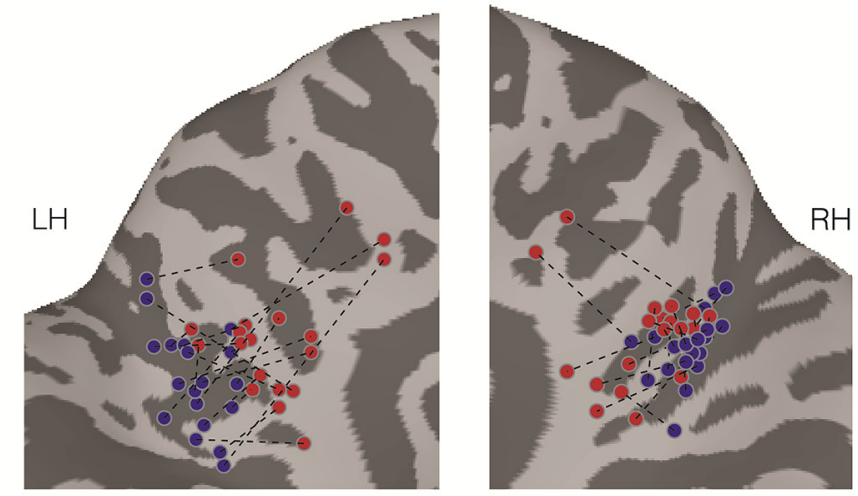

B
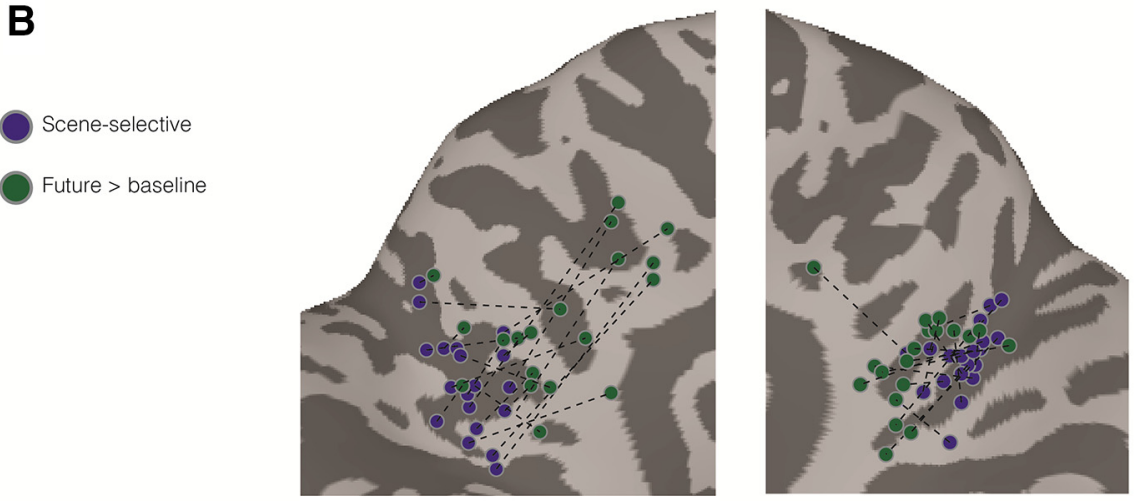

Figure 6. Comparison of the posterior-anterior location of perceptual and mnemonic peaks in both hemispheres. $\boldsymbol{A}, \mathrm{A}$ medial view of the left hemisphere of a single participant is shown with the medial parietal cortex highlighted in red. Enlarged versions of medial parietal cortex are shown for both the left and right hemispheres. Overlaid onto these enlarged surfaces are the peak responses of scene selectivity (blue circles) and Remember $>$ Baseline (red circles) for each participant. Dashed black line connects the corresponding peaks for each participant. Across participants, there is a consistent anterior shift in the peak for remembered events, such that this peak never occurs more posterior than the peak for scene selectivity. $\boldsymbol{B}$, Same as in $\boldsymbol{A}$, but for Future $>$ Baseline. Except for 1 participant in the right hemisphere, the same anterior shift is present.

memory-based scene reconstruction within RSC. Based on independent studies by our own group (Gilmore et al., 2016, 2018; Silson et al., 2016) and others (Baldassano et al., 2013, 2017; Marchette et al., 2014, 2015), we predicted that perceptual responses would be localized to posterior portions of RSC (i.e., the MPA), whereas mnemonic responses would be localized more anteriorly. The double dissociation we observe between MPA and CON supports a general posterior-anterior distinction within the broader RSC. Further, these data reinforce previous concerns regarding the inherent inaccuracy associated with "RSC" as a cortical label (or relatedly, in treating "default" regions of medial parietal cortex as homogeneous). Our data also identified an apparent left hemispheric advantage for mnemonic responses and, finally, suggest the fundus of the POS as a landmark for the transition between perceptual and mnemonic representations.

\section{Perceptual responses are posterior to mnemonic responses in RSC}

RSC has been implicated in visual perception (Epstein and Higgins, 2007; Baldassano et al., 2013, 2016; Silson et al., 2016), spatial navigation (Marchette et al., 2014, 2015), and episodic memory retrieval (Vilberg and Rugg, 2008; Ranganath and Ritchey, 2012). Here, we demonstrate that memory-based constructions of both remembered past and imagined future events are anterior of perceptual representations of scenes. Indeed, per- ceptual responses of scenes in MPA were significantly greater than in $\mathrm{CON}$, but mnemonic responses were significantly greater in CON than in MPA. A qualitatively similar posterior-anterior division was also present on the lateral surface and to a lesser extent the ventral surface. In the current study, we were unable to quantify this division outside of medial parietal cortex, but this is a goal of future work.

While the ROI analyses demonstrate a double dissociation between scene perception and scene construction, they do not directly speak to the location in RSC where this crossover may occur. Our analyses of the relative posterior-anterior response profiles revealed a striking difference between tasks, with perceptual responses rising sharply and peaking posterior of the fundus of POS, before decreasing steadily more anteriorly in both hemispheres. In contrast, mnemonic responses increased more gradually, peaking anterior of the fundus of POS, with the largest difference between profiles occurring at the anterior bank of POS, extending into the posterior cingulate and precuneus. These data suggest the fundus of POS as the potential crossover point between perceptual and mnemonic representations, but the anterior bank of POS as the location where these representations become maximally separable, consistent with a number of previous resting-state parcellations of RSC that identified the anterior gyrus of POS as the transition point between different parcels (Power et al., 2011; Yeo et al., 2011; Shirer et al., 2012; Laumann et al., 2015). Similarly, anatomical parcellations have suggested a transition near this gyrus (Brodmann, 1909; Tzourio-Mazoyer et al., 2002). Thus, multiple lines of evidence converge upon POS as a functional transition point between perception and more abstract representations, such as those elicited when constructing scenes from memory. However, given the inherent low resolution and smoothness of fMRI data, relative to underlying neural architecture, one should interpret these data as suggestive of as opposed to definitively identifying a precise anatomical landmark.

An intriguing question concerns how to best interpret the overlap observed between the MPA and CON ROIs within the framework of the posterior-anterior division we report. It is possible that the overlapping region simply reflects an uninteresting side-effect of interindividual variability, smoothing or statistical thresholding within the current dataset. In such cases, overinterpreting the presence of overlap may lead to the spurious conclusion of a third identifiable RSC subregion. Alternatively, it is also possible that the overlapping region indicates the presence of a "convergence zone" for both bottom-up perceptual/externally driven information and top-down constructive/internally driven information. To distinguish between these alternative possibilities will require higher resolution than was used in this study. A complimentary approach could be to use a small $N$, high data design (e.g., Laumann et al., 2015; Braga and Buckner, 2017; 


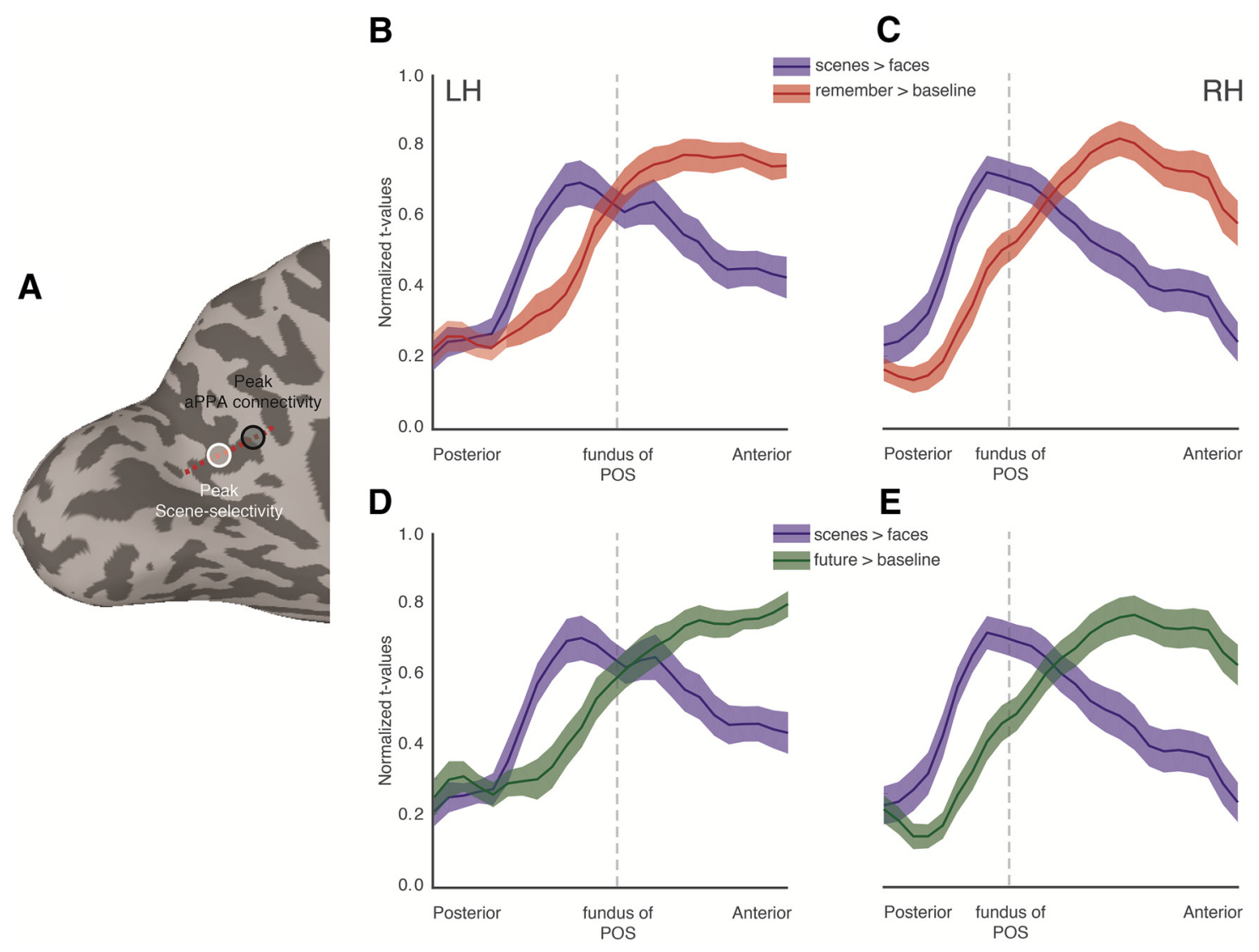

Figure 7. Posterior-anterior perceptual and mnemonic response profiles. $A$, A medial view of the left hemisphere is shown of a single participant. White circle represents the group-based peak of scene selectivity. Black circle represents the group-based peak of aPPA connectivity. Red dashed line indicates the trajectory of the line ROl which runs directly through the center of these peaks from posterior to anterior. $\boldsymbol{B}$, Lines indicate the group-average normalized selectivity profiles for both the perceptual (blue line represents $S$ cenes $>$ Faces) and mnemonic (red line represents Remember $>$ Baseline) conditions, as a function of posterior-anterior position through the line ROI. At posterior portions of the POS, the relative strength of both conditions is largely comparable. More anteriorly, perceptual responses show a sharp rise, peaking posterior of the fundus of the POS (dashed vertical line) and then deteriorating gradually thereafter. In contrast, mnemonic representations show a more gradual increase, peaking anterior of the fundus of the POS and becoming maximally separable from perceptual representations at anterior portions of POS. C, Same as in $\boldsymbol{A}$, but for the right hemisphere. $\boldsymbol{D}, \boldsymbol{E}$, Same as in $\boldsymbol{A}$ and $\boldsymbol{B}$, but for Future $>$ Baseline. In each case, solid line indicates the mean across participants and the shaded region represents the SEM across participants.

Gordon et al., 2017). Such an approach would avoid the need to average across anatomies.

\section{Imprecision of RSC as a cortical label}

The present findings highlight the inherent imprecision using "RSC" and join other recent results suggesting that the posterior medial parietal cortex is not a homogeneous processing entity. For instance, work in highly sampled individuals has highlighted that cortex stretching from ventral RSC to the precuneus consists of interdigitated representations of several networks, including the default, contextual association, and frontoparietal and parietal memory networks (Braga and Buckner, 2017; Gordon et al., 2017). Other recent work using intracranial recordings also indicates functional heterogeneity within medial parietal cortex, even in a contiguous patch putatively within the default network (Daitch and Parvizi, 2018; Fox et al., 2018). Thus, small, specific functional-anatomic labels are increasingly important when discussing regions within medial parietal cortex.

Whereas "MPA" was intended to imply a putative functional role (Silson et al., 2016), the label "CON" was originally intended as a shortening of "connectivity-defined" and was meant to be neutral with respect to the function of the region. Here, we found evidence that processes associated with memory-based scene construction appear to be preferentially supported by CON relative to MPA, consistent with a possible role in navigation and memory. However, despite scene construction being strongly associated with episodic memory retrieval and episodic future thought, the "memory" task used here is not process pure, and includes information related to people, objects, and so on (Roberts et al., 2018; for recent discussion, see Palombo et al., 2018a). We have therefore elected to refrain from renaming "CON" at this time, pending future work that might better elucidate the functional properties of this and other regions in anterior "RSC".

\section{Hemispheric differences in mnemonic responses}

A consistent feature of our data is an apparent left hemisphere advantage for both remembered and imagined future events. A left-hemisphere advantage has been remarked upon in prior neuroimaging studies of human memory but is most frequently discussed in the context of recognition memory studies. These often produce highly left-lateralized activation patterns (for metaanalytic evidence, see, e.g., Wagner et al., 2005; McDermott et al., 2009; Spaniol et al., 2009), particularly when materials are verbalizable (McDermott et al., 1999; Kim, 2013). However, in studies of autobiographical memory, strong laterality effects are less frequently discussed (but see Svoboda et al., 2006), and extant 
meta-analyses generally reflect bilaterality in region responses (Svoboda et al., 2006; McDermott et al., 2009; Benoit and Schacter, 2015). However, upon close inspection, one can observe evidence of left-hemisphere advantages in recent studies of episodic memory and future thought, even when significant effects are observed bilaterally (Addis et al., 2007; Szpunar et al., 2009; Gilmore et al., 2016, 2018; Chen et al., 2017). We offer several tentative possibilities as to why a hemispheric asymmetry might be observed, and suggest that future experiments be mindful of subtle, but potentially informative, laterality effects.

We begin by noting that hemispheric asymmetries are also consistent with both neuropsychological and neuroimaging studies of mental imagery, a cognitive mechanism that our participants engaged presumably during the memory task (Rubin, 2005; Palombo et al., 2018b); this is further supported by the correlations we observed between the VVIQ and postscan questionnaires completed by our participants. For example, left temporo-occipital damage has been linked with image generation deficits (Farah, 1984; Farah et al., 1988; Goldenberg, 1992; Stangalino et al., 1995), although lesion data have not specifically included RSC regions. In addition, a left hemisphere advantage for tasks involving mental rotation (Cohen, 1975) and mental imagery of letters (Farah et al., 1985; Kosslyn et al., 1985) as well as other mental imagery tasks (Corballis and Sergent, 1988) have been reported in several patients who underwent callosotomy surgery, so-called "split-brain" patients (Farah et al., 1985; Kosslyn et al., 1985; Corballis and Sergent, 1988). However, this apparent left hemisphere advantage has also been shown to be either reduced (Kosslyn et al., 1985) or absent (Corballis and Sergent, 1988; Sergent and Corballis, 1990) with increased task experience and thus should be interpreted with caution. Finally, eventrelated potential (Farah and Peronnet, 1989) and fMRI (Farah, 1995; D’Esposito et al., 1997) studies in healthy controls using auditory cues, paired either with or without subsequent mental imagery, also report a left hemisphere advantage.

Of course, pinpointing the precise anatomical source of such an advantage, if one is even present, is challenging. Both the lesion data and fMRI data in healthy controls point to posterior portions of the occipitotemporal cortex, but a finer localization is less clear. We do not interpret our data as identifying the region just anterior to left MPA as the source of mental imagery ability; rather, the apparent left hemisphere advantage in this region likely reflects its involvement in mental imagery and scene construction from memory (Vann et al., 2009; Ranganath and Ritchey, 2012; McDermott and Gilmore, 2015; Robin, 2018); in the case of the $\mathrm{CON}$, this is presumably the generation of spatial contexts in which the events were taking place. We cannot, however, rule out definitively the role of language and/or internal verbalization in this apparent left hemisphere advantage, although why this effect would be present in anterior portions of RSC, and to a lesser degree aPPA, is hard to reconcile with a purely language engagement account.

In conclusion, together, our data reveal that perceptual representations of scenes in RSC are posterior of mnemonic representations of constructed scenes in the same group of participants, questioning the utility of overly broad cortical labels, such as "RSC." Instead, our data suggest that a finer distinction within RSC (and medial parietal cortex more broadly) is required, and future studies should focus on identifying the functional contribution of these different parcels. These data also suggest the fundus of POS as an anatomical landmark for the representational crossover from perceptual to mnemonic and, further, highlight the anterior bank of POS and adjacent cortex as a region for maximal differentiation between these representations. Such observations are consistent with resting-state parcellations of RSC, but crucially are demonstrated here by comparing perceptual and mnemonic responses directly. Finally, the data also suggest a lefthemisphere advantage in autobiographical memory retrieval, an advantage that should be interpreted with caution but does not typically receive broad attention.

\section{References}

Addis DR, Wong AT, Schacter DL (2007) Remembering the past and imagining the future: common and distinct neural substrates during event construction and elaboration. Neuropsychologia 45:1363-1377. CrossRef Medline

Arnold KM, McDermott KB, Szpunar KK (2011) Individual differences in time perspective predict autonoetic experience. Conscious Cogn 20:712719. CrossRef Medline

Baldassano C, Beck DM, Fei-Fei L (2013) Differential connectivity within the parahippocampal place area. Neuroimage 75:228-237. CrossRef Medline

Baldassano C, Esteva A, Fei-Fei L, Beck DM (2016) Two distinct sceneprocessing networks connecting vision and memory. eNeuro 3:ENEURO0178. CrossRef Medline

Baldassano C, Chen J, Zadbood A, Pillow JW, Hasson U, Norman KA (2017) Discovering event stricture in continuous narrative perception and memory. Neuron 95:709-721.e5. CrossRef Medline

Bar M, Aminoff E (2003) Cortical analysis of visual context. Neuron 38: 347-358. CrossRef Medline

Benoit RG, Schacter DL (2015) Specifying the CORE network supporting episodic simulation and episodic memory by activation likelihood estimation. Neuropsychologia 75:450-457. CrossRef Medline

Braga RM, Buckner RL (2017) Parallel interdigitated distributed networks within the individual estimated by intrinsic functional connectivity. Neuron 95:457-471.e5. CrossRef Medline

Brodmann K (1909) Vergleichende Lokalisationslehre der Grosshirnrinde in ihren Prinzipien dargestellt auf Grund des Zellenbaues. Leipzig, Germany: Barth.

Buckner RL, Andrews-Hanna JR, Schacter DL (2008) The brain's default network: anatomy, function, and relevance to disease. Ann N Y Acad Sci 1124:1-38. CrossRef Medline

Chen HY, Gilmore AW, Nelson SM, McDermott KB (2017) Are there multiple kinds of episodic memory? An fMRI investigation comparing autobiographical and recognition memory tasks. J Neurosci 37:2764-2775. CrossRef Medline

Chrastil ER, Sherrill KR, Aselcioglu I, Hasselmo ME, Stern CE (2017) Individual differences in human path integration abilities correlate with gray matter volume in retrosplenial cortex, hippocampus, and medial prefrontal cortex. eNeuro 4:ENEURO-0346. CrossRef Medline

Cohen C (1975) Hemispheric differences in the effects of cuing in visual recognition tasks. J Exp Psychol Hum Percept Perform 1:366-373. CrossRef Medline

Corballis MC, Sergent J (1988) Imagery in a commissurotomized patient. Neuropsychologia 26:13-26. CrossRef Medline

Cox RW (1996) AFNI: software for analysis and visualization of functional magnetic resonance images. Comput Biomed Res 29:162-173. CrossRef Medline

Crovitz HF, Schiffman H (1974) Frequency of episodic memories as a function of their age. Bull Psychonom Soc 4:517-518. CrossRef

Daitch AL, Parvizi J (2018) Spatial and temporal heterogeneity of neural responses in human posteromedial cortex. Proc Natl Acad Sci U S A 115: 4785-4790. CrossRef Medline

D'Argembeau A, Van der Linden M (2004) Phenomenal characteristics associated with projecting oneself back into the past and forward into the future: influence of valence and temporal distance. Conscious Cogn 13: 844-858. CrossRef Medline

D’Esposito M, Detre JA, Aguirre GK, Stallcup M, Alsop DC, Tippet LJ,Farah MJ (1997) A functional MRI study of mental image generation. Neuropsychologia 35:725-730. CrossRef Medline

Epstein RA (2008) Parahippocampal and retrosplenial contributions to human spatial navigation. Trends Cogn Sci 12:388-396. CrossRef Medline 
Epstein RA, Higgins JS (2007) Differential parahippocampal and retrosplenial involvement in three types of visual scene recognition. Cereb Cortex 17:1680-1693. CrossRef Medline

Farah MJ (1984) The neurological basis of mental imagery: a componential analysis. Cognition 18:245-272. CrossRef Medline

Farah MJ (1995) Current issues in the neuropsychology of image generation. Neuropsychologia 33:1455-1471. CrossRef Medline

Farah MJ, Peronnet F (1989) Event-related potentials in the study of mental imagery. J Psychophysiol 3:99-109.

Farah MJ, Gazzaniga MS, Holtzman JD, Kosslyn SM (1985) A left hemisphere basis for visual mental imagery? Neuropsychologia 23:115-118. CrossRef Medline

Farah MJ, Hammond KM, Levine DN, Calvanio R (1988) Visual and spatial mental imagery: dissociable systems of representation. Cogn Psychol 20: 439-462. CrossRef Medline

Fox KC, Foster BL, Kucyi A, Daitch AL, Parvizi J (2018) Intracranial electrophysiology of the human default network. Trends Cogn Sci 22:307324. CrossRef Medline

Gilmore AW, Nelson SM, McDermott KB (2015) A parietal memory network revealed by multiple MRI methods. Trends Cogn Sci 19:534-543. CrossRef Medline

Gilmore AW, Nelson SM, McDermott KB (2016) The contextual association network activates more for remembered than for imagined events. Cereb Cortex 26:611-617. CrossRef Medline

Gilmore AW, Nelson SM, Chen HY, McDermott KB (2018) Task-related and resting-state fMRI identify distinct networks that preferentially support remembering the past and imagining the future. Neuropsychologia 110:180-189. CrossRef Medline

Goldenberg G (1992) Loss of visual imagery and loss of visual knowledge: a case study. Neuropsychologia 30:1081-1099. CrossRef Medline

Gordon EM, Laumann TO, Gilmore AW, Newbold DJ, Greene DJ, Berg JJ, Ortega M, Hoyt-Drazen C, Gratton C, Sun H, Hampton JM, Coalson RS, Nguyen AL, McDermott KB, Shimony JS, Snyder AZ, Schlaggar BL, Petersen SE, Nelson SM, Dosenbach NU (2017) Precision functional mapping of individual human brains. Neuron 95:791-807.e7. CrossRef Medline

Hassabis D, Kumaran D, Maguire EA (2007) Using imagination to understand the neural basis of episodic memory. J Neurosci 27:14365-14374. CrossRef Medline

Kim H (2013) Differential neural activity in the recognition of old versus new events: an activation likelihood estimation meta-analysis. Hum Brain Mapp 34:814-836. CrossRef Medline

Kim JG, Aminoff EM, Kastner S, Behrmann M (2015) A neural basis for developmental topographic disorientation. J Neurosci 35:12954-12969. CrossRef Medline

Kosslyn SM, Holtzman JD, Farah MJ, Gazzaniga MS (1985) A computational analysis of mental image generation: evidence from functional dissociations in split-brain patients. J Exp Psychol Gen 114:311-341. CrossRef Medline

Kundu P, Inati SJ, Evans JW, Luh WM, Bandettini PA (2012) Differentiating BOLD and non-BOLD signals in fMRI time series using multi-echo EPI. Neuroimage 60:1759-1770. CrossRef Medline

Kundu P, Brenowitz ND, Voon V, Worbe Y, Vértes PE, Inati SJ, Saad ZS, Bandettini PA, Bullmore ET (2013) Integrated strategy for improving functional connectivity mapping using multiecho fMRI. Proc Natl Acad Sci U S A 110:16187-16192. CrossRef Medline

Kundu P, Voon V, Balchandani P, Lombardo MV, Poser BA, Bandettini PA (2017) Multi-echo fMRI: a review of applications in fMRI denoising and analysis of BOLD signals. Neuroimage 154:59-80. CrossRef Medline

Laumann TO, Gordon EM, Adeyemo B, Snyder AZ, Joo SJ, Chen MY, Gilmore AW, McDermott KB, Nelson SM, Dosenbach NU, Schlaggar BL, Mumford JA, Poldrack RA, Petersen SE (2015) Functional system and areal organization of a highly sampled individual human brain. Neuron 87:657-670. CrossRef Medline

MacEvoy SP, Epstein RA (2007) Position selectivity in scene- and objectresponsive occipitotemporal regions. J Neurophysiol 98:2089-2098. CrossRef Medline

Marchette SA, Vass LK, Ryan J, Epstein RA (2014) Anchoring the neural compass: coding of local spatial reference frames in human medial parietal lobe. Nat Neurosci 17:1598-1606. CrossRef Medline

Marchette SA, Vass LK, Ryan J, Epstein RA (2015) Outside looking in: landmark generalization in the human navigational system. J Neurosci 35: 14896-14908. CrossRef Medline
Marks DF (1973) Visual imagery differences in the recall of pictures. Br J Psychol 64:17-24. CrossRef Medline

McDermott KB, Buckner RL, Petersen SE, Kelley WM, Sanders AL (1999) Set- and code-specific activation in the frontal cortex: an fMRI study of encoding and retrieval of faces and words. J Cogn Neurosci 11:631-640. CrossRef Medline

McDermott KB, Gilmore AW (2015) The role of context in understanding similarities and differences in remembering and episodic future thinking. Psychol Learn Motiv 63:45-76. CrossRef

McDermott KB, Szpunar KK, Christ SE (2009) Laboratory-based and autobiographical retrieval tasks differ substantially in their neural substrates. Neuropsychologia 47:2290-2298. CrossRef Medline

Miezin FM, Maccotta L, Ollinger JM, Petersen SE, Buckner RL (2000) Characterizing the hemodynamic response: effects of presentation rate, sampling procedure, and the possibility of ordering brain activity based on relative timing. Neuroimage 11:735-759. CrossRef Medline

Mitchell AS, Czajkowski R, Zhang N, Jeffery K, Nelson AJ (2018) Retrosplenial cortex and its role in spatial cognition. Brain Neurosci Adv 2:2398212818757098. CrossRef Medline

Morris R, Paxinos G, Petrides M (2000) Architectonic analysis of the human retrosplenial cortex. J Comp Neurol 421:14-28. CrossRef Medline

Mullally SL, Maguire EA (2014) Memory, imagination, and predicting the future: a common brain mechanism? Neuroscientist 20:220-234. CrossRef Medline

Nasr S, Liu N, Devaney KJ, Yue X, Rajimehr R, Ungerleider LG, Tootell RB (2011) Scene-selective cortical regions in human and nonhuman primates. J Neurosci 31:13771-13785. CrossRef Medline

Palombo DJ, Hayes SM, Peterson KM, Keane MM, Verfaellie M (2018a) Medial temporal lobe contributions to episodic future thinking: scene construction for future projection? Cereb Cortex 28:447-458. CrossRef Medline

Palombo DJ, Sheldon S, Levine B (2018b) Individual differences in autobiographial memory. Trends Cogn Sci 22:583-597. CrossRef Medline

Park S, Chun MM, Johnson MK (2010) Refreshing and integrating visual scenes in scene-selective cortex. J Cogn Neurosci 22:2813-2822. CrossRef Medline

Peirce JW (2007) PsychoPy: psychophysics software in Python. J Neurosci Methods 162:8-13. CrossRef Medline

Power JD, Cohen AL, Nelson SM, Wig GS, Barnes KA, Church JA, Vogel AC, Laumann TO, Miezin FM, Schlaggar BL, Petersen SE (2011) Functional network organization of the human brain. Neuron 72:665-678. CrossRef Medline

Power JD, Plitt M, Gotts SJ, Kundu P, Voon V, Bandettini PA, Martin A (2018) Ridding fMRI data of motion-related influences: removal of signals with distinct spatial and physical bases in multiecho data. Proc Natl Acad Sci U S A 115:E2105-E2114. CrossRef Medline

Ranganath C, Ritchey M (2012) Two cortical systems for memory-guided behaviour. Nat Rev Neurosci 13:713-726. CrossRef Medline

Roberts RP, Schacter DL, Addis DR (2018) Scene construction and relational processing: separable constructs? Cereb Cortex 28:1729-1732. CrossRef Medline

Robin J (2018) Spatial scaffold effects in event memory and imagination. Wiley Interdiscip Rev Cogn Sci 23:e1462. CrossRef Medline

Rubin DC (2005) A basic systems approach to autobiographical memory. Curr Directions Psychol Sci 14:79-83. CrossRef

Sergent J, Corballis MC (1990) Generation of multipart images in the disconnected cerebral hemispheres. Bull Psychonom Soc 28:309-311. CrossRef

Shirer WR, Ryali S, Rykhlevskaia E, Menon V, Greicius MD (2012) Decoding subject-driven cognitive states with whole-brain connectivity patterns. Cereb Cortex 22:158-165. CrossRef Medline

Silson EH, Steel AD, Baker CI (2016) Scene selectivity and retinotopy in medial parietal cortex. Front Hum Neurosci 10:412. CrossRef Medline

Spaniol J, Davidson PS, Kim AS, Han H, Moscovitch M, Grady CL (2009) Event-related fMRI studies of episodic encoding and retrieval: metaanalyses using activation likelihood estimation. Neuropsychologia 47: 1765-1779. CrossRef Medline

Stangalino C, Semenza C, Mondini S (1995) Generating visual mental 
images: deficit after brain damage. Neuropsychologia 33:1473-1483. CrossRef Medline

Svoboda E, McKinnon MC, Levine B (2006) The functional neuroanatomy of autobiographical memory: a meta-analysis. Neuropsychologia 44: 2189-2208. CrossRef Medline

Szpunar KK, Chan JC, McDermott KB (2009) Contextual processing in episodic future thought. Cereb Cortex 19:1539-1548. CrossRef Medline

Tzourio-Mazoyer N, Landeau B, Papathanassiou D, Crivello F, Etard O, Delcroix N, Mazoyer B, Joliot M (2002) Automated anatomical labeling of activations in SPM using a macroscopic anatomical parcellation of the MNI MRI single-subject brain. Neuroimage 15:273-289. CrossRef Medline
Vann SD, Aggleton JP, Maguire EA (2009) What does the retrosplenial cortex do? Nat Rev Neurosci 10:792-802. CrossRef Medline

Vilberg KL, Rugg MD (2008) Memory retrieval and the parietal cortex: a review of evidence from a dual-process perspective. Neuropsychologia 46:1787-1799. CrossRef Medline

Wagner AD, Shannon BJ, Kahn I, Buckner RL (2005) Parietal lobe contributions to episodic memory retrieval. Trends Cogn Sci 9:445-453. CrossRef Medline

Yeo BT, Krienen FM, Sepulcre J, Sabuncu MR, Lashkari D, Hollinshead M, Roffman JL, Smoller JW, Zöllei L, Polimeni JR, Fischl B, Liu H, Buckner RL (2011) The organization of the human cerebral cortex estimated by intrinsic functional connectivity. J Neurophysiol 106:1125-1165. CrossRef Medline 